\title{
UMA DISCRETA CONTROVÉRSIA? Acerca de duas licenças presentes na História da América Portuguesa de Rocha Pitta
}

\author{
Marcone Zimmerle Lins Aroucha*
}

RESUMO: Este artigo empreende um exercício interpretativo a propósito de duas licenças presentes na História da América Portuguesa, de Sebastião da Rocha Pitta. Licenças escritas por António Rodrigues da Costa e de D. António Caetano de Souza (membros da Academia Real da História Portuguesa). A partir destas construções textuais, buscamos analisar parte do processo de aprovação da referida obra na tentativa de compreender as expectativas de adequação da prosa historiográfica no âmbito da Academia Real da História.

PALAVRAS-CHAVE: Academia Real da História; Historiografia Moderna; Prosa historiográfica; Império Português.

\section{A discrete controversy?}

Concerning two licenses present in the History of Portuguese America by Rocha Pitta

ABSTRACT: This article undertakes an interpretative exercise regarding two publishing licenses present in Sebastião da Rocha Pitta's História da América Portuguesa ("History of Portuguese America"). Said licenses were written by António Rodrigues da Costa and D. António Caetano de Souza (members of the Royal Academy of Portuguese History). Looking at these textual constructions, we analyze the approval process of the work in question, in an attempt to understand the expectations of adequacy of historiographic prose within the sphere of the Royal Academy of Portuguese History.

KEYWORDS: Royal Academy of History; Modern Historiography; Historiographical Prose; The Portuguese Empire.

\section{¿Una discreta controversia? \\ Acerca de dos licencias presentes en la História da América Portuguesa de Rocha Pitta}

RESUMEN: En este artículo se lleva a efecto un ejercicio de interpretación respecto a dos licencias presentes en la História da América Portuguesa, de Sebastião da Rocha Pitta. Licencias escritas por Antonio Rodrigues da Costa y D. António Caetano de Souza (miembros de la Academia Real da História Portuguesa). A partir de estas construcciones textuales, buscamos analizar parte del proceso de aprobación de la referida obra en el intento de comprender las expectativas de adecuación de la prosa historiográfica en el ámbito de la Academia Real da História.

PALABRAS CLAVE: Academia Real de la Historia; Historiografía Moderna; Prosa historiográfica; Imperio portugués.

\footnotetext{
* Mestre em História pela Universidade Federal de Pernambuco. Atualmente é doutorando do Programa de PósGraduação em História pela mesma universidade, bolsista da Coordenação de Aperfeiçoamento de Pessoal de Nível Superior (CAPES). Contato: Avenida Afonso Olindense, Várzea, CEP: 50810-000, Recife,PE, Brasil. E-mail: marcone.zimmerle@gmail.com. ORCID: https://orcid.org/0000-0002-2985-2624.
} 
No século XVIII, durante o reinado de D. João V, verificou-se um esforço consciente por parte da Coroa Portuguesa de formalizar, instituir e padronizar parâmetros metodológicos para diferentes áreas do conhecimento; tratava-se, grosso modo, de um projeto de fortalecimento de técnicas e especializações ${ }^{1}$. Esta tendência se encontra no contexto das relações diplomáticas portuguesas durante a Guerra de Sucessão Espanhola e dos debates sobre os territórios dos Impérios Ibéricos. Debates que frequentaram a diplomacia, cartografia e historiografia da época, para ficarmos em alguns exemplos ${ }^{2}$. De modo que não nos parece descabido conjecturar que o amadurecimento do fazer diplomático lusitano ocorreu no contexto da formação de uma República das Letras entre os homens de pena portugueses com outros cenáculos europeus. A pesquisa de campo empreendida por Manuel Caetano de Sousa - em atendimento de incumbência régia - nas academias europeias, quando da gestação da Academia Real de História Portuguesa, não deixa de ser um encontro entre política externa e demanda erudita - uma vez que envolveu, além da interação direta entre acadêmicos estrangeiros, a reunião de um corpus de manuscritos e impressos para benefício da nascente academia régia ${ }^{3}$.

A propósito do campo historiográfico lusófono, o imperativo de formalização da escrita da história teve um capítulo importante com a criação da Academia Real da História Portuguesa, em 1720. A fundação da Academia Real constituiu, de um lado, um amadurecimento das confrarias letradas já existentes em Portugal desde meados do século XVII e, de outro, a expressão de imperativos políticos e geopolíticos ciosos para com a soberania do Império Português ${ }^{4}$. Porque a Academia Real poderia estabelecer, organizar e realizar narrativas eruditas acerca da história lusitana e de suas conquistas, logrando assim uma legitimidade histórica do que seriam suas glórias e possessões ultramarinas (de certa maneira, essa mesma atribuição vassálica conferida à História verificou-se na fundação, na América Portuguesa, da Academia Brasílica dos Esquecidos, em 1724, e, posteriormente, da dos Renascidos, fundada em 1759) ${ }^{5}$.

Legitimidade histórica, dissemos. Importa considerar que tal legitimidade não é auferida apenas pela credibilidade intelectual obtida por pesquisas de indiscutível rigor. No Antigo Regime português, o quem escreve a história tinha significados sociais que se infiltravam nas realizações intelectuais. Em outras palavras: há muita diferença entre uma história escrita por um fidalgo da Casa Real e uma história escrita por alguém desprovido de algum grau ou título de nobreza. A esse propósito, é possível encontrar em frontispícios de obras acadêmicas a posição social de indivíduos ligados à cultura escrita: no Engenheiro 
Portuguez, seu autor, Manoel de Azevedo Fortes, tem os predicados arrolados no frontispício. Predicados que asseveram sua autoridade intelectual e social: “(...) Manoel de Azevedo Fortes, acadêmico da Academia Real da História Portugueza, Cavalleiro professo na Ordem de Cristo, Brigadeiro de Infanteria dos Exércitos de sua Majestade e Engenheiro mór destes Reinos, etc.”6 . O mesmo se aplica a Sebastião da Rocha Pitta na sua História da América Portuguesa:

(...) Sebastião da Rocha Pitta, Fidalgo da Casa de Sua Majestade, Cavalleiro professo da Ordem de Cristo, Coronel do Regimento da Infantaria da Ordenança da Cidade da Bahia, e dos Privilegiados dela, e Acadêmico Supranumerário da Academia Real da História Portugueza ${ }^{7}$.

Os frontispícios supracitados exemplificam a colaboração simbólica travada entre honrarias (fidalgo da Casa Real e cavaleiro da Ordem de Cristo) e atribuição especializada (acadêmico, engenheiro, etc.). A um só tempo, sua interação reforça os significados nobiliárquicos e consolidam a autoridade do que se está a escrever (sobre um passado, sobre um território, etc.). Se tomarmos como um pressuposto - à luz da tratadística sobre a nobreza produzida na Idade Moderna - que é inerente ao "arquétipo fidalgo" a palavra fidedigna ${ }^{8}$, o relato insuspeito, poderemos depreender que o conteúdo de uma obra erudita escrita, por exemplo, por um fidalgo da Casa Real terá uma função política específica: o que se diz, o que se enquadra e o que se defende na sua produção monográfica é pura verdade - tendo em vista o valor atribuído à sua posição no vocabulário social; ora, o efeito de verdade já se encontra assegurado pela própria instituição, uma academia real. Trata-se, portanto, de um núcleo de credibilidade alicerçado em bases eruditas, nobiliárquicas e régias. Acresce ainda que há uma distribuição de capital simbólico: o que sai dos prelos da Academia Real é produção de gente nobilitada e aquele que nela ingressa tem seu prestígio social acrescentado com a qualificação de acadêmico ${ }^{9}$.

Em esquema, o quadro dirigente da Academia Real da História era composto pelo diretor, pelo secretário e pelos censores. Os dois primeiros desempenhavam tarefas políticas e administrativas, seja na organização das conferências, seja nas relações entre a Academia e o rei. Quanto aos censores, além da significativa contribuição no campo administrativo (porque as matérias das conferências e o ingresso de novos membros também compunham a sua alçada), estes tinham um papel crucial na formação das regras do jogo historiográfico ${ }^{10}$.

Em seu estudo sobre a Academia Real da História Portuguesa, Isabel Ferreira da Mota $^{11}$ procurou explicar a construção de um "campo historiográfico" na esteira da formalização dos métodos para a escrita histórica. Com efeito, ao lermos as notícias das 
conferências da Academia, podemos verificar que a formação da instituição se encontra intimamente ligada às diretrizes teórico-metodológicas construídas nos debates acadêmicos ${ }^{12}$.

Donde se tira que a institucionalização da escrita histórica não deriva, e não pode derivar, de uma naturalização do que se entendia por escrita histórica; esta era um objeto de rica discussão. Ainda que a escrita da história tenha estabelecido estreito contato com o poder régio, seu rigor intelectual não precisa ser vulnerável à desconfiança das nossas percepções contemporâneas sobre o conhecimento histórico. Como defende Richard Kagan, a história oficial construída na Época Moderna não pode ser vista como uma operação erudita de curto alcance cultural $^{13}$. Mas essa formalização da escrita histórica não se manifestou via uma uniformização teórico-metodológica, mas pela controvérsia e embate de paradigmas narrativos e retóricos díspares como o encômio, a genealogia e a poesia.

As próximas linhas tentarão sondar, à luz da institucionalização da prosa historiográfica processada no âmbito da Academia Real, uma realidade de bastidor. Buscaremos analisar parte do processo de aprovação de uma obra na tentativa de compreender as eruditas e desencontradas expectativas de adequação de escrita histórica. E esta obra é a História da América Portuguesa, de Sebastião da Rocha Pitta.

\section{A Academia Real nas aprovações da História da América Portuguesa de Rocha Pitta}

O presente artigo tem por objetivo construir uma análise de certos aspectos que parecem emergir do braço paratextual da História da América Portuguesa de Sebastião da Rocha Pitta, e por "braço paratextual" entenda-se os textos presentes em uma obra que não fazem parte de seu conteúdo nuclear (ou seja, advertências ao leitor, pareceres das licenças que formalizarão a impressão do livro etc. $)^{14}$.

O recorte temporal da História de Rocha Pitta se inicia no século XVI e vai até 1724 . O tema de sua obra - o passado da América Portuguesa - constitui um valor em si mesmo para as disposições políticas de seu tempo. Valor declarado tanto pelo autor quanto pelos seus colegas acadêmicos que escreveram as aprovações da obra (e, levando em conta o poder institucional da Academia Real, tal valor deveria ser muito bem visto por D. João V). Encadear eventos da, àquela altura, importante conquista do Império Português, se afigura como a construção de um discurso de legitimação simbólica e material tanto daquela praça como do mesmo Império - razão pela qual a obra de Rocha Pitta deva ser considerada, de saída, um serviço ao rei ${ }^{15}$. De todo modo, há de se perguntar como se deu a recepção da obra 
entre os acadêmicos. Esta pergunta pode ser parcialmente respondida a partir da leitura de alguns componentes paratextuais da mesma.

A História de Rocha Pitta busca atender aos critérios de verdade da Academia Real; pelo menos assim o declara, embora admita que sua prosa em algum momento se desvie de tais preceitos, mas apressa-se em justificar que tal desvio deve-se a uma imposição de seu objeto de estudo, especificamente quando trata dos aspectos naturais da América Portuguesa; aspectos estes que obrigam uma concepção de verdade mais próxima à construção poética que ao rigor historiográfico:

\footnotetext{
Que como nos dous primeiros livros descreve o corpo natural, e material desta Região, as maravilhosas obras, que nela fez a natureza, as admiráveis produções em vários gêneros, e espécies, e as suntuosas fábricas, que para o trato Civil, e Político das suas Povoações foi compondo a arte, no retrato de tanta, fermosura, precisada a ser pincel a pena, não teme sair dos preceitos da História, quando altera a pureza das suas leis com as ideias da pintura, que requer mais valentes fantasias, tendo por exemplar portentos, em que a mais elevada frase Poética é verdade ainda mal encarecida ${ }^{16}$.
}

Pode-se entrever, na passagem supracitada, uma composição de modelos retóricos. De um lado, a prosa artística, com seus preceitos burilados já nos alvores da Época Moderna Ibérica, tanto com a ampla acolhida do diálogo, gênero literário cultivado entre os renascentistas italianos na esteira da tradição dos diálogos platônicos ${ }^{17}$, quanto com a recepção das formulações de Quintiliano a propósito do caráter imagético de uma retórica talhada para fornecer uma compreensão ampla e imediata (evidentia). Mais do que ser ouvida ou lida, a enunciação oral e a construção prosística devem estar "diante dos olhos" de quem ouve e de quem lê, como numa pintura ${ }^{18}$.

Nesse sentido, seria necessária uma análise aturada da maneira como essa convenção verificada no Siglo de Oro espanhol aparece na prosa setecentista de Rocha Pitta - ao declarar que modelou e subverteu as "leis" da História a partir de princípios da pintura, o autor baiano pode nos estar dando um testemunho da incorporação da metáfora pictórica à estruturação da prosa.

Em estudo introdutório à sua edição crítica do Tratado Político de Rocha Pitta, Eduardo Sinkevisque, no exercício que faz de incluir a prosa histórica de Pitta nos paradigmas historiográficos dos séculos XVII e XVIII, delineia os atributos do texto do historiador baiano: "Tem-se com isso uma prosa historiográfica encomiástica, metafórica ou alegórica, que se aproxima de modelos da pintura, em uma espécie de ut pictura historia"19. 
A esse respeito, talvez caiba conjecturarmos que os efeitos buscados por uma, digamos, abordagem pictórica, ou imagética, da retórica pode, em alguma medida, ser uma sobrevivência de procedimentos mnemônicos descritos e explicados em tratados como o $\mathrm{Ad}$ Herennnium (autor anônimo), o De oratore de Cícero, o Institutio oratoria de Quintiliano e, já no medievo, as contribuições da escolástica (notadamente de Tomás de Aquino) para a arte da memória. Grosso modo, este rico repertório disserta sobre imagens mentais - incluídas em lugares igualmente abstratos - elaboradas para referenciar de modo mais eficaz aquilo que se deseja lembrar (sejam palavras, sejam coisas) ${ }^{20}$. Este parece ser um método que trava certo nível de correspondência com uma prosa que busca descrever em filigrana um lugar, por exemplo - no caso da História de Pitta este lugar seria o chão (e as águas) da América Portuguesa. Está claro, entretanto, que se há de fato procedência na relação entre os preceitos da mnemônica clássica e a prosa imagética, tal relação deriva, acima de tudo, do fato de que, conforme os antigos tratados de retórica, a mnemônica, o panegírico e a evidentia integram a arte retórica - portanto, seus nexos devem-se mais a uma matriz teórica comum do que a semelhanças diretas ${ }^{21}$.

Mas regressemos à copiosa enumeração narrativa do meio natural luso-americano presente na prosa de Pitta. Consta que a descrição da natureza é uma convenção de chave bíblica e mitológica ${ }^{22}$, de modo que essa escolha narrativa de Rocha Pitta responde a um conjunto de topoi referentes ao ordenamento do mundo, à Mãe Natura ${ }^{23}$. Estas convenções se encontram amplamente distribuídas no tempo longo. No medievo, a prosa ibérica já cultivava narrativas - inclusive historiográficas, por assim dizer - que tinham na descrição da natureza um papel de suma importância ${ }^{24}$.

Ademais, é possível que a formação da prosa fabular ou de peripécia tenha encontrado na descrição da natureza e, por extensão, do espaço geográfico, um importante recurso que emprestava movimento ao conteúdo encadeado ${ }^{25}$. Mesmo os romances de cavalaria - muito lidos na Península Ibérica dos séculos XVI e XVII ${ }^{26}$ - costumavam traduzir o estado de ânimo dos seus personagens (quando à beira da aventura ou na ocasião do arrebatamento amoroso) a partir da descrição da natureza ${ }^{27}$. Trata-se, portanto, de uma grossa meada cultural desdobrada na diacronia.

De resto, há de se perguntar se a obra de Rocha Pitta constitui um reflexo do entrelaçamento - acentuado desde os tempos de Aldo Manuzio - dos preceitos da poética e da retórica aristotélicas na Europa Moderna ${ }^{28}$ (bem como nos seus prolongamentos americanos). Tal entrelaçamento é particularmente notável nas formas de fabulação ${ }^{29}$, mas talvez fosse o 
caso de investigá-lo na constituição da prosa historiográfica lusitana. A esse propósito, consideramos que as palavras de Luís Reis Torgal sobre o estado da dialética e da retórica em Portugal no século XVII merecem uma análise que vá até o século XVIII ${ }^{30}$. O que importa reter no momento é que, da declaração de princípios de Rocha Pitta, podemos retirar um exemplo do caráter compósito da escrita histórica no mundo lusófono da Época Moderna ${ }^{31}$.

Donde tiramos que indagar acerca da configuração do discurso em prosa no mundo lusófono da primeira metade do século XVIII é lidar com a consolidação de um imperativo de formalização da escrita histórica processada de permeio com tradições retóricas e fabulares. Imperativo corporificado, como já foi dito, com a criação da Academia Real da História em 1720. Mas essa formalização da escrita histórica não se manifestou apenas através de uma uniformização institucional, mas pela controvérsia e embate de paradigmas narrativos e retóricos díspares. É sintomático que a primeira das aprovações da História de Rocha Pitta declare com algum veneno:

Em execução da ordem de Vossas Excelências vi o livro, intitulado História da América Portuguesa, composta pelo Coronel Sebastião da Rocha Pitta; e ainda que me parece mais elogio, ou panegírico, que História, não entendo, que desmerece o Author, que Vossas Excellencias lhe concedam a faculdade, que pede de poder condecorar o seu nome na edição, que fizer desta obra, com o título, que goza de Acadêmico Provincial desta Academia Real da História Portuguesa. Vossas Excelências ordenarão o que for mais justo ${ }^{32}$.

Eis o parecer de António Rodrigues da $\operatorname{Costa}^{33}$. Embora conciso em suas cerca de dez linhas, a ressalva que estas desferem abre a possibilidade de uma discreta controvérsia.

A controvérsia parece se tornar mais evidente na aprovação seguinte, da lavra de D. António Caetano de Souza $^{34}$ :

\begin{abstract}
Esta História, Excelentíssimos Senhores, é a única, que temos seguida, e completa dos dilatados, e riquíssimos Domínios, que El Rei nosso Senhor tem nesta grande parte do Mundo; pelo que é muito de agradecer a curiosa aplicação, com que seu Autor se empregou em escrever esta História, que sendo principalmente política, tem muito de natural, pelo que se faz mais agradável, não só pela notícia dos seus preciosos minerais, mas pela de inumeráveis animais terrestres, quadrúpedes, répteis, e voláteis, monstros horríveis, ainda aquáticos, porque aqueles mares produzem cousas de grande admiração, como também o são as vegetáveis, com tão extraordinárias produções da natureza, que fazem fertilíssima aquela grande porção de terra, compreendida debaixo do domínio do nosso Augusto Protetor ${ }^{35}$.
\end{abstract}

Emitida em novembro de 1726 (pouco mais de três meses depois da aprovação escrita por António Rodrigues da Costa), a aprovação de D. Caetano de Souza parece exaltar o tom que Rodrigues da Costa considerava ser "mais panegírico que história": no caso, a narração de 
recursos naturais e o zelo para com o ornato da prosa ${ }^{36}$. Evidentemente que tal desencontro de vozes não é extraordinário ${ }^{37}$. O que nos parece pertinente considerar, no entanto, é o desafio intelectual que o impasse impõe aos acadêmicos: como seguir de perto a verdade posta da "glória" de um passado sem o uso do elogio? Acreditamos que esta pergunta é por demais simples para a resposta que provavelmente a espera. As "Advertências" de Rocha Pitta e os pareceres de António Rodrigues da Costa e D. António Caetano de Souza tracejam um rastro que parece nos levar a um quadro de intrincados princípios de erudição ${ }^{38}$.

Conforme estabelece o Systema da Historia Ecclesiastica, \& Secular de Portugal, que há de escrever a Academia Real da História Portuguesa - opúsculo que circulou impresso entre os acadêmicos em 03 de fevereiro de 1721 e cujo propósito é o de estabelecer normas de estruturação temática das narrativas historiográficas -, quando a matéria a ser historiada é alguma conquista ultramarina, deve-se proceder (além da descrição do ordenamento político) à "notícia dos animais, plantas, e minerais, e descrição das costas, e interior do País (...)"39. Esta passagem figura na seção do Systema reservada às "Observações particulares para a História Secular".

É significativo que a recomendação de descrever a natureza das conquistas (estas especificadas pelas partes da África e América Portuguesa), bem como os seus respectivos sertões, não se encontra quando o espaço a ser narrado é o próprio Reino lusitano. E a razão disso parece clara: a preocupação em estabelecer o território das conquistas. Nesse sentido, Rocha Pitta segue de perto tais diretrizes. Diretrizes não tão objetivas, contudo, são aquelas relativas à forma. Novamente citamos o Systema: "As Memórias, da História de Portugal serão escritas na língua Portuguesa com estilo puro, e claro, próprio deste assunto (...)"40.

Assim, segundo o Systema, a prosa deve ter "estilo puro, e claro, próprio deste assunto". Há aqui o que pode ser uma magra sugestão a respeito do ajustamento da forma com o tema que a mesma ajudará a desdobrar. A frase citada nos evoca a passagem das "Advertências" de Rocha Pitta, onde este justifica sua prosa poeticamente derramada pela concordância com a excelência natural de seu objeto historiográfico. Nas mesmas "Advertências" o autor não deixa de chamar a atenção, contudo, que teve o cuidado de observar seus procedimentos narrativos sempre de acordo com os quadros temáticos presentes na obra. Assim escreveu referindo-se aos livros (ou seja, aos capítulos) que se seguiriam àqueles que privilegiavam a descrição, em cores poéticas, do mundo natural da América Portuguesa:

Que nos outros livros, que contém matérias Políticas, leva o estilo Histórico com estudo castigado, e não põe nas margens os numerosos rios, e as várias espécies das 
produções do Brasil, porque sendo tanto do instituto desta obra, entende, que devem ir no corpo dela ${ }^{41}$.

A esse respeito, é possível encontrar um eco de Aristóteles, que em sua Retórica escreveu:

\begin{abstract}
A expressão possuirá a forma conveniente se exprimir emoções e caracteres, e se conservar a 'analogia' com os assuntos estabelecidos. Há analogia se não se falar grosseiramente acerca de assuntos importantes, nem solenemente de assuntos de pouca monta, nem se se colocarem ornamentos numa palavra vulgar. Se assim não for, assemelha-se a um registro de comédia ${ }^{42}$.
\end{abstract}

Não obstante, as linhas normativas do Systema acerca da forma são um tanto difusas para sugerirem que havia algum preceito retórico escrupulosamente delineado. Em todo caso, parece-nos cabível considerar que a observância entre a forma e o conteúdo requerida pelo Systema (“... estilo puro, e claro, próprio deste assunto”) não foi de nenhuma maneira acidental. Tal diretriz retórica amparou-se numa tradição que, como vimos, é tributária da retórica aristotélica. Ademais, o referido princípio constituiu um verdadeiro topos historiográfico no século XVII ibérico, princípio este explicitamente enunciado por um Cabrera de Cordoba: "El historiador cuenta por médio de la oración, enseña de necesidad y deleita con suavidad, con palabras elegantes, con arte colocadas y eligidas, por más convenientes a las cosas que se han de decir, para que sea suave y grave la narración"43.

No que podemos encontrar, aqui, uma explicação provisória acerca do descompasso de acadêmicos nas aprovações da História da América Portuguesa. Aquele espaço paratextual informa, talvez, um debate sobre a escrita da história. Um debate que parecia estar ainda tomando corpo. Não nos esqueçamos que o processo de escrita e edição da História de Rocha Pitta coincidiu com a primeira década da Academia Real da História. De modo que o padrão de qualidade da mesma poderia estar em constante problematização. Convém ressaltar que tais assuntos de forma não se apresentavam, naquele contexto, como preocupações meramente disciplinares. Esses debates pertenciam a um conjunto de compromissos à Monarquia. Em outras palavras: o projeto de uma história institucionalizada e, portanto, oficial é um ato de serviço ao $\operatorname{Rei}^{44}$.

De maneira que a descrição floreada da natureza da conquista luso-americana presente em Rocha Pitta é uma expressão poética, por assim dizer, de um inventário que visa à fixação de um território ${ }^{45}$. Entretanto, seria simplista sugerir que a "má vontade" de António Rodrigues da Costa configurasse uma tácita desaprovação de definir narrativamente o território de tão rica conquista. Segundo outro membro da Academia Real, Barbosa Machado, em sua Biblioteca Lusitana, o mesmo António Rodrigues da Costa planejava escrever sua 
própria história ultramarina. Este dado pode ser revelador, uma vez que essa empresa erudita, determinada pela Academia Real, seria uma "História Ultramarina na língua Latina"46.

Com efeito, Rodrigues da Costa parecia ter qualificações insuspeitas para a tarefa, com o seu pleno domínio do latim. Em paralelo, sua experiência em embaixadas diplomáticas e a condição que auferiu como deputado do Conselho Ultramarino certamente lhe conferiram uma dimensão empírica da geopolítica do Império Português ${ }^{47}$. Aparentemente, tal obra não chegou a ser concluída, sobrando apenas a "elegantemente escrita" introdução da mesma, impressa na "Coleção dos Monumentos da mesma Academia do ano de 1721"

Por agora, não travamos contato com tal introdução. Mas o que no momento nos interessa é a informação de um projeto de história do ultramar português em latim. Projeto este que parece colocar mais um elemento para se construir uma compreensão acerca da formalização do discurso historiográfico lusitano no Setecentos: os níveis de instrumentalização política de uma prosa vernácula e uma outra classicista. Lembremos que a Academia, através das normas do Systema, também projetava histórias escritas em vernáculo. E isto está longe de se afigurar uma incoerência regimental.

Uma história latina do Ultramar português quadrava muito bem no propósito da Academia de divulgar ao mundo as glórias do Império lusitano - ou seja, uma história para uma República das Letras, uma história para diplomata ler. Por seu turno, uma história em vernáculo, como a escrita por Rocha Pitta, tinha o mesmo propósito triunfalista, embora sua abrangência compreendesse estritamente o mundo lusófono e, talvez, o peninsular - contudo, não podemos perder de vista a possibilidade de que a obra do historiador baiano estivesse na mesma esteira de preocupações diplomáticas e cartográficas que permearam a política internacional do tempo de D. João $\mathrm{V}$, política que, ademais, integrou os processos de discussões que resultaram no Tratado de Madrid ${ }^{49}$.

De toda maneira, o que é certo é que esses dois tipos de história tinham demandas tipográficas diferentes. Demandas que podem voltar alguma luz à autoconsciência de Rocha Pitta para com a sua prosa e ao sutil enfado de Rodrigues da Costa para com a mesma. No sexto tomo de seu Vocabulário Português publicado em 1720, Rafael Bluteau recorda que o panegírico é acessório discursivo que integra, na arte retórica, o gênero demonstrativo. De modo que o comentário de Rodrigues da Costa ao caráter "panegírico" da História de Rocha Pitta pode representar uma crítica quanto à observância da adequação de gêneros retóricos à prosa historiográfica. Também não deve ter escapado ao classicista do Conselho Ultramarino uma implicação elementar do panegírico: a amplidão de seu público receptor. Novamente 
Bluteau pontifica: "porque para ouvir um Panegírico se ajunta muita gente" ${ }^{, 50}$. Talvez a vetusta polêmica do ensino e do deleite esteja a reverberar no parecer de Rodrigues da Costa $^{51}$.

No entanto, a despeito do que pode sugerir a ressalva de Rodrigues da Costa sobre o panegírico, este não era estranho à escrita histórica. Como recorda Alcir Pécora,

Essa determinação do panegírico acentua certamente a compreensão tradicional da forma historiográfica como subgênero do epidítico, que censura ou elogia no presente ou, mais do que isso, produz a excelência ou a baixeza do sujeito que predica $^{52}$.

E continua: “(...) o panegírico exige destreza no emprego de procedimentos elocutivos assentados sobretudo na acuidade, ou seja, na descrição que produz o efeito de proximidade visual diante do movimento das ações narradas" ${ }^{\circ 3}$. Portanto, aparece novamente a aplicação de um senso imagético num discurso em prosa. A levar em conta a supracitada reflexão de Pécora, a obra de Rocha Pitta se inscreve nos padrões de escrita histórica de seu tempo; entretanto, o sugestivo "senão" sublinhado por Rodrigues da Costa pode apontar que as linhas metodológicas do fazer historiográfico da Academia Real estavam em construção.

De resto, levando em conta o tradicional pendor do panegírico de se expressar para multidões, as palavras de Rodrigues da Costa podem sugerir uma postura que coloca a escrita histórica como uma produção feita para poucos leitores. A esse propósito, voltemos ao adversário de circunstância, e colega de Academia, deste último. Em outro passo de sua aprovação à História da América Portuguesa, D. António Caetano de Souza assim se expressa:

Este Autor [Rocha Pitta] o faz em estilo tão elegante, que tem muito de Poético, em que lhe acho companheiros de tão grande nota, como algum de eminentíssimo caráter, e este será o motivo, porque concilie na maior parte dos Leitores o aplauso, e louvor; porque entendo, que não será menos estimada esta História, do que outras, que vemos de semelhante estilo na nossa língua, e na dos nossos vizinhos, aonde tem bastante reputação. Por diferentes meios conciliam os Autores a aura popular com que os seus livros são estimados. Os exemplares da História Romana, cuja lição é tão recomendável a um Historiador, vemos quão poucos os que logram o cabal nome de Historiadores. Quantas vezes ouvimos criticar aqueles Mestres da História, de quem os outros, que se seguiram, beberam não só o método, mas ainda o mesmo estilo? Nesta parte são bem diversos os gostos, porque também alguns enfastiados da eloquência, pretendem seja a História uma narração tão nua de vozes como de reflexões, de sorte, que a querem antes insulsa, que com algum adorno; porém estes discursos são tidos de uns por paradoxos, e de outros por afectos da melancolia, que os domina de modo, que o não chegam a executar nesta parte ainda os mais austeros Censores. Este livro me parece mui digno da licença, que seu Autor pede, para o ornar com o nome de Acadêmico da nossa Real Academia ${ }^{54}$. 
Ao que parece, a exuberância das "vozes" ressoadas na prosa de Rocha Pitta não exclui sua obra - aos olhos de D. António Caetano de Souza - do gênero historiográfico. Ao contrário: teria muito perdido sua escrita se estivesse ela aferrada à aridez de certos “exemplares da História Romana”. Há de se perguntar o que um António Rodrigues da Costa poderia retrucar a respeito de tal parecer. Há também de se considerar o seguinte: dessa polêmica sutil, uma realidade correlata a essas matérias de estilo precisa ser incluída numa reflexão que se propõe sondar a construção de uma historiografia oficial. E esta realidade correlata é a imprensa. "Realidade correlata", dissemos. Em verdade, trata-se de um pano de fundo dessas meditações historiográficas. Trata-se do que será e do que não será impresso - e a Academia Real da História, com seu corpo censório interno e independente do Santo Ofício, tinha o poder para uma decisão dessa natureza.

O procedimento censório da Academia, bem como sua autonomia em relação a órgãos de censura exteriores (ou seja, os do Santo Ofício e os do Desembargo do Paço) são temas que merecem, acreditamos, um estudo aprofundado. Porque, ao considerarmos o fato de que alguns dos acadêmicos tinham ligações profissionais mais ou menos estreitas com os referidos órgãos, há de se perguntar até que ponto houve, na Academia, influências das tradições de censura eclesiástica e secular, tanto no horizonte da morfologia discursiva quanto nos parâmetros concernentes a um determinado ideal de cultura escrita. Tais questões, por agora, têm apenas um valor propositivo. No entanto, acreditamos que estas podem conduzir a uma compreensão mais aprofundada da "política cultural" - para usarmos um termo recorrente no estudo de Isabel Ferreira da Mota - no tempo de D. João V, política manifesta nas interações e desencontros de instituições distintas.

A esse respeito, gostaríamos de reservar mais algumas palavras acerca das implicações do aparelhamento censório da instituição aqui em apreço. A autonomia censória verificada na Academia Real da História se encontra - pedimos licença para novamente recordar - na desobrigação das obras impressas sob seu aval para com os escrúpulos do Desembargo do Paço, do Santo Ofício e de outros “órgãos responsáveis pela censura” como os representados pelo bispo e pelas ordens religiosas ${ }^{55}$. Este fato abre para uma reflexão a propósito do estado da composição de poderes no campo da cultura escrita. No que tange ao campo historiográfico, as deliberações e meditações teórico-metodológicas da Academia parecem ter recortado um novo segmento de poder censório nas complexas dinâmicas de emissão e recepção da cultura escrita. Porque ao formar um corpo de censura independente, a Academia estabelece novos "horizontes de expectativa" 56 acerca de obras eruditas. Em outras palavras, 
as obras eruditas ganham o verniz de "eruditas" porque passaram pelo crivo verdadeiramente adequado para julgá-las como tal, a saber, o crivo acadêmico ${ }^{57}$. A centralização da censura promovida pela Academia provavelmente guardava em si uma dimensão prática alinhada aos interesses de politização do passado lusitano: ao concentrar o ato da censura numa única instituição, a margem de tempo para a circulação de obras historiográficas diminuía sobremaneira, uma vez que o número de atores sociais incumbidos dos pareceres tendencialmente seria menor - e as eventuais polêmicas de conteúdo se apresentariam mais em termos teórico-metodológicos do que necessariamente morais e/ou religiosos (ainda que tais dimensões não perdessem o seu peso nos critérios de publicação). De todo modo, acreditamos que muito se há por investigar a esse propósito ${ }^{58}$.

\section{Considerações finais}

A partir do exercício interpretativo que no presente artigo esboçamos, consideramos estar diante de um fragmento que murmura um debate profundo acerca dos componentes historiográficos da prosa lusitana - bem como das suas implicações no âmbito de critérios tipográficos. Sobretudo: esta incipiente sondagem nos permite encontrar na Academia Real um repositório de tradições discursivas construídas no tempo longo.

Com efeito, faz-se necessário ampliar o corpus para melhor dimensionar os padrões prosísticos das obras históricas do Portugal da Época Moderna. Em termos cronológicos, parece-nos conveniente considerar textos anteriores à fundação da Academia Real. Em termos políticos, deve-se pensar a escrita da história na esteira da construção da Monarquia Bragantina ${ }^{59}$.

Portanto, se se quiser um recorte que abarque todo o calendário das turbulências políticas, das batalhas nos espaços sul-atlânticos e nas fronteiras peninsulares - bem como as batalhas discursivas amparadas por manuscritos e pela palavra impressa - o ano de 1640 parece constituir um ponto de partida. Por outro lado, se considerarmos obras históricas de envergadura como a História Geral das Guerras Angolanas de António de Oliveira de Cadornega $^{60}$ e a História do Portugal Restaurado do Conde de Ericeira ${ }^{61}$ e analisá-las à luz de uma construção de critérios e parâmetros retóricos a serem amadurecidos a partir da primeira metade do século XVIII (com a fundação da Academia Real), podemos construir uma leitura aprofundada do fazer historiográfico sob a Dinastia dos Bragança, sobretudo nos tempos de D. Pedro II e D. João V. Foi no período de regência e reinado do primeiro em que 
houve um relativo distanciamento para a leitura de um passado recente: a Restauração; foi no tempo de D. João V em que preocupações geopolíticas e empreendimentos eruditos se entrelaçaram de modo mais profundo.

De maneira que, sob esta luz, a fundação da Academia Real se afigura como um ponto de chegada de uma investigação debruçada na configuração da escrita histórica no Império Português dos séculos XVII e XVIII. Ao que nos parece, tal investigação ainda se está por fazer.

\title{
Notas
}

\begin{abstract}
${ }^{1}$ MOTA, Isabel Ferreira da. A Academia Real da História - os intelectuais, o poder cultural e o poder monárquico no séc. XVIII. Coimbra: Edições Minerva, 2003; KANTOR, Iris. Esquecidos e Renascidos: historiografia acadêmica lusoamericana (1724-1759). São Paulo: Hucitec; Salvador, BA: Centro de Estudos BaianoslUFBA, 2004; FURTADO, Júnia Ferreira. Guerra, diplomacia e mapas: a Guerra da Sucessão Espanhola, o Tratado de Utrecht e a América portuguesa na cartografia de D' Anville. Topoi, v. 12, n. 23, jul-dez. 2011, p. 66-83.
\end{abstract}

${ }^{2}$ CLUNY, Isabel. A Guerra de Sucessão de Espanha e a Diplomacia Portuguesa. Penélope, no 26, 2002, pp. 63-92.;

KANTOR, Iris. Esquecidos e Renascidos: historiografia acadêmica luso-americana (1724-1759). São Paulo: Hucitec; Salvador, BA: Centro de Estudos BaianosIUFBA, 2004; MOTA, Isabel Ferreira da. A Academia Real da História - os intelectuais, o poder cultural e o poder monárquico no séc. XVIII. Coimbra: Edições Minerva, 2003; FURTADO, Júnia Ferreira. Guerra, diplomacia e mapas: a Guerra da Sucessão Espanhola, o Tratado de Utrecht e a América portuguesa na cartografia de D' Anville. Topoi, v. 12, n. 23, jul-dez. 2011, p. 66-83.

${ }^{3}$ Sobre as pesquisas de Manuel Caetano de Sousa, cf. KANTOR, Iris. Esquecidos e Renascidos..., p. 42.

${ }^{4}$ PESSOTI, Bruno Casseb. Ajuntar manuscritos, e convocar escritores: o discurso histórico institucional no setecentos luso-brasileiro. Dissertação apresentada ao Programa de Pós-Graduação em História, Faculdade de Filosofia e Ciências Humanas, Universidade Federal da Bahia, como requisito parcial para obtenção do grau de Mestre em História. Salvador, 2009 , p. 41.

${ }^{5}$ Idem; KANTOR, Iris, op. cit.

${ }^{6}$ Cf. FORTES, Manuel de Azevedo. O Engenheiro Portuguez (2 tomos). Lisboa Ocidental: Na Oficina de Manoel Fernandes da Costa, 1728.

${ }^{7}$ Cf. PITTA, Sebastião da Rocha. História da América Portuguesa, desde o anno de mil e quinhentos do seu descobrimento, até o ano mil e setecentos e vinte e quatro. Lisboa Ocidental, na Oficina de Joseph Antonio da Silva, impressor da Academia Real, 1730.

${ }^{8}$ Cf. SOARES, Sérgio Cunha. Nobreza e Arquétipo Fidalgo - A propósito de um Livro de Matrículas de Filhamentos (1641-1724). Revista de História das Ideias. Vol. 19, 1997.

${ }^{9}$ Este aspecto torna-se evidente no âmbito da Academia Real da História. Conforme Isabel Ferreira da Mota: “(...) Pertencer à Academia Real implicava também uma relação de fidelidade ao rei, que se traduz na acção política como enviados ou representantes do monarca e que se traduz nas obras como construtores da sua glória". Cf. MOTA, Isabel Ferreira da. A Academia Real da História..., p. 208. Pode-se considerar, portanto, que as práticas acadêmicas do Setecentos cultivaram as permutas características dos padrões de relação vertical entre rei e vassalos. Dito de outro modo: estavam tais práticas inseridas na economia de mercês. Para assuntos de economia de mercês e liberalidade régia no Antigo Regime português, cf. OLIVAL, Fernanda. As Ordens Militares e o Estado Moderno - honra, mercê e venalidade em Portugal (1641-1789). Estar, 2001; XAVIER, Ângela Barreto \& HESPANHA, António Manuel. Redes Clientelares in MATTOSO, José \& HESPANHA, António Manuel. História de Portugal - O Antigo Regime. Editorial Estampa, 1998.

${ }^{10} \mathrm{Cf}$. MOTA, Isabel Ferreira da. A Academia Real da História - os intelectuais, o poder cultural e o poder monárquico no séc. XVIII. Coimbra: Edições Minerva, 2003.

${ }^{11}$ MOTA, Isabel Ferreira da. A Academia Real da História - os intelectuais, o poder cultural e o poder monárquico no séc. XVIII. Coimbra: Edições Minerva, 2003.

${ }^{12}$ Cf. Coleção dos documentos, estatutos e memórias da Academia Real da História Portuguesa, que neste ano de 1721, se compuseram e se imprimiram por ordem dos censores, dedicada a el rei nosso senhor, seu augustissímo protetor e ordenada pelo conde de Villamayor, secretário da mesma academia. Lisboa Ocidental, na oficina de Pascoal da Sylva, Impresso de S. Magestade Real. MDCCXXI.

${ }^{13}$ KAGAN, Richard. Los cronistas y la Corona: la política de la historia en España en las Edades Media y Moderna. Madri: Centro de Estudios Europa Hispánica, 2010. 


\begin{abstract}
${ }^{14}$ Sobre a noção de paratexto, cf. BURKE, Peter. As fortunas d'O cortesão: a recepção europeia a O Cortesão de Castiglione. São Paulo: Editora da Universidade Estadual Paulista, 1997. Ademais, importa sublinhar que o exercício interpretativo que se vai esboçar neste artigo é em muito tributário a determinados trabalhos de Carlo Ginzburg que procedem a análises morfológicas. Cf. GINZBURG, Carlo. Mitologia germânica e nazismo: sobre um velho livro de Georges Dumézil; Freud, o homem dos lobos e os lobisomens in GINZBURG, Carlo. Mitos, Emblemas, Sinais: morfologia e história. São Paulo: Companhia das Letras, 2014. Entretanto, tais referências não constituem exatamente contributos para um nosso arcabouço teórico-metodológico, uma vez que este não se acha desenvolvido. De modo que este é ainda um texto que se fecha em si mesmo; um texto que se propõe mais em experimentar modelos de explicação do que fornecer explicações a respeito de nossa matéria de interesse.

${ }^{15}$ A propósito da História da América Portuguesa de Rocha Pitta - além da sua pertinência historiográfica na maturação da ideia de território na América - podemos depreender que do termo "América Portuguesa" subjaz um intento de separar o "opulento Império do Brasil" da outra América, ou seja, a América Espanhola. Nesse sentido, o ouro das Minas Gerais serve de comparação à Prata de Potosí. A um só tempo, tanto desfaz o valor comercial que as montanhas argênteas logravam para Castela como também exalta o respiro econômico de Portugal. Respiro este representado pelo ouro em detrimento dos exauridos veios de prata da conquista espanhola. Em outras palavras, o título da referida obra parece antecipar uma competição discursiva de glórias ultramarinas entre os Impérios Ibéricos. Naturalmente, sob a pena de Rocha Pitta, a conquista lusitana leva a melhor Cf. PITTA, Sebastião da Rocha. História da América Portuguesa, desde o anno de mil e quinhentos do seu descobrimento, até o ano mil e setecentos e vinte e quatro. Lisboa Ocidental, na Oficina de Joseph Antonio da Silva, impressor da Academia Real, 1730, p. 09. Sobre a ideia de território no século XVIII, cf. KANTOR, op. cit.
\end{abstract}

16 PITTA, Sebastião da Rocha. História da América Portuguesa, desde o anno de mil e quinhentos do seu descobrimento, até o ano mil e setecentos e vinte e quatro. Lisboa Ocidental, na Oficina de Joseph Antonio da Silva, impressor da Academia Real, 1730. A passagem citada se encontra na última página das "Advertências" (não há paginação).

${ }^{17}$ BOUZA, Fernando. Del Escribano a la Biblioteca - La Civilización Escrita Europea en la Alta Edad Moderna (Siglos XV-XVII). Madrid: Editorial Síntesis, 1997.

${ }^{18}$ GRIGERA, Luisa López. Sobre el realismo literário Del Siglo de Oro. Actas del VIII Congreso de la Asociación Internacional de Hispanistas, 1986.

${ }^{19}$ SINKEVISQUE, Eduardo. Historiarum Copia, História Seleta: O Tratado Político (1715) de Sebastião da Rocha Pita in Pita, Sebastião da Rocha. Tratado Político (1715). Estudo introdutório, transcrição, índices, notas e estabelecimento do texto por Eduardo Sinkevisque; prefácio de João Adolfo Hansen. São Paulo: Edusp, 2014, p. 23.

20 "Não é difícil apreender os princípios gerais da mnemônica. O primeiro passo era imprimir na memória uma série de loci, lugares. O tipo mais comum de sistema mnemônico de lugares utilizado, embora não fosse o único, era o tipo arquitetônico. A melhor descrição do processo é dada por Quintiliano. Segundo ele, para formar uma série de lugares na memória, deve-se recordar uma construção a mais ampla e variada possível, com o pátio, a sala de estar, os quartos, os salões, sem omitir as estátuas e outros ornamentos que decoram esses espaços. As imagens por meio das quais o discurso será lembrado - como um exemplo delas, Quintiliano diz que se pode utilizar uma âncora ou uma arma - são, então, colocadas pela imaginação em lugares da construção que foram memorizados. Isso feito, tão logo a memória dos fatos precise ser reavivada, percorrem-se todos esses lugares sucessivamente e pede-se a seus guardiões aquilo que foi depositado em cada lugar". YATES, Frances Amelia. A Arte da Memória. Campinas: Editora da Unicamp, 2007, p. 19.

${ }^{21}$ YATES, Frances Amelia. A Arte da Memória. Campinas: Editora da Unicamp, 2007; ALEXANDRE JÚNIOR, Manuel. Introducão in ARISTÓTELES. Retórica. São Paulo: Editora WMF Martins Fontes, 2012; PÉCORA, Alcir. A história como colheita rústica de excelências in SCHWARTZ, Stuart e PÉCORA, Alcir (org.) As excelências do governador: 0 panegírico fúnebre a d. Afonso Furtado, de Juan Lopes Sierra (Bahia, 1676). São Paulo: Companhia das Letras, 2002; GRIGERA, Luisa López. Sobre el realismo literário Del Siglo de Oro. Actas del VIII Congreso de la Asociación Internacional de Hispanistas, 1986.

${ }^{22}$ REDONDO, Fernando Gómez. Historia de la Prosa Medieval Castellana, I - La creación del discurso prosístico: el entramado cortesano. Madrid: Cátedra, 1998.

${ }^{23}$ CURTIUS, Ernest Robert. Literatura Europeia e Idade Média Latina. São Paulo: Hucitec: Edusp, 1996.

${ }^{24}$ REDONDO, op. cit.

${ }^{25}$ MORETTI, Franco. Romance: história e teoria. São Paulo: Novos estudos - CEBRAP número 85, 2009.

${ }^{26}$ CASTRO, Ivo. Sobre a data da introdução na Península Ibérica do ciclo arturiano da Post-Vulgata. Bulletin of Hispanic Studies, 1975; AGUILAR PERDOMO, María del Rosario. La recepción de los libros de caballerías en el siglo XVI: a propósito de los lectores en el Quijote. Literatura: teoría, historia, crítica 7 (2005): pp. 45-67; DÍAZ-TOLEDO, Aurelio Vargas. Os livros de cavalarias renascentistas nas histórias da literatura portuguesa. Universidad Complutense de Madrid/Centro de Estudios Cervantinos. Península. Revista de Estudos Ibéricos, no 3, 2006: 233-247.

${ }^{27}$ GOUVEIA FERNANDES, Raúl Cesar \& MAUÉS, Fernando. Introdução - Pela Fé, Pelo Império, Por Amor in MORAES, Francisco de. Palmeirim de Inglaterra. Cotia: Ateliê Editorial; Campinas: Editora da Unicamp, 2016, p. 36, nota 59.

${ }^{28}$ GRIGERA, Luisa López. Anotações de Quevedo à Retórica de Aristóteles. Campinas: Editora da UNICAMP, 2008.

${ }^{29}$ ALEXANDRE JÚNIOR, Manuel. Introducão in ARISTÓTELES. Retórica. São Paulo: Editora WMF Martins Fontes, 2012; BERRIO, Antonio García. El "patrón” renacentista de Horacio y los tópicos teórico-literarios del Siglo de Oro español. Actas del cuarto Congreso Internacional de Hispanistas, 1971; LAÍlLA, Luis Sánchez. "Dice Aristóteles": la reescritura de la Poética en los Siglos de Oro. CRITICÓN. Número 79 (2000).

30 “(...) apesar da importância da escolástica, no século XVII já não existe a ideia absoluta de que a obra política deveria revestir a forma de um tratado teorético. Cada vez mais e à medida que a retórica ia substituindo a dialéctica como arte 
discursiva, parece ter-se a noção de que tais escritos deveriam ser facilmente captáveis, de maneira que a lição por eles transmitida pudesse ser aprendida sem dificuldade". TORGAL, Luís Reis. Ideologia Política e Teoria do Estado na Restauração (2 vols.). Coimbra: Biblioteca Geral da Universidade, 1981, p. 122.

${ }^{31}$ Com "caráter compósito" estamos a nos referir a distintos modelos de prosa que se infiltram na escrita histórica (segmentos da arte retórica, diálogos, construções fabulares, tratadísticas etc.).

${ }^{32}$ Aprovacão de António Rodrigues da Costa in PITTA, op. cit. Não paginada. Os itálicos são nossos.

${ }_{33}$ Foi "do Conselho de Sua Majestade, e do seu Tribunal do Ultramar, Academico da Academia Real da História". Cf. a licença escrita por António Rodrigues da Costa in PITTA, Sebastião da Rocha. História da América Portuguesa, desde o anno de mil e quinhentos do seu descobrimento, até o ano mil e setecentos e vinte e quatro. Lisboa Ocidental, na Oficina de Joseph Antonio da Silva, impressor da Academia Real, 1730. As licenças não se encontram paginadas.

34 "Clérigo Regular, Qualificador do Santo Ofício, Consultor da Bula da Santa Cruzada, e Academico da Academia Real da História”. Cf. a licença escrita por D. António Caetano de Souza in PITTA, Sebastião da Rocha. História da América Portuguesa, desde o anno de mil e quinhentos do seu descobrimento, até o ano mil e setecentos e vinte e quatro. Lisboa Ocidental, na Oficina de Joseph Antonio da Silva, impressor da Academia Real, 1730. As licenças não se encontram paginadas.

35 Aprovação de D. António Caetano de Souza in PITTA, op. cit. Não paginada.

${ }^{36}$ Neste ponto é preciso reconhecer um limite nada pequeno de nossa estrutura argumentativa: as razões que fundamentaram Rodrigues da Costa a apontar um feitio mais panegírico que historiográfico à obra de Rocha Pitta não são detalhadas na sua aprovação. No entanto, considerando a proximidade das datas de sua aprovação e de seu colega de Academia, D. António Caetano de Souza, bem como a função institucional que ambas desempenham na inscrição de Rocha Pitta como acadêmico supranumerário (ver nota 38), entendemos ser plausível que as duas aprovações estabelecem uma relação de contraste: a primeira põe em dúvida o valor historiográfico da obra e a segunda, ao contrário, afirma tal valor. De modo que há, segundo nossa leitura, uma "discreta controvérsia".

${ }^{37}$ Além das aprovações de António Rodrigues da Costa e D. António Caetano de Souza, há outras quatro. Estas, no entanto, não serão objeto de nossa análise. Nosso critério de delimitação é simples: imediatamente seguida às duas aprovações que aqui nos interessam, há a seguinte disposição, subscrita pelo diretor e censores da Academia Real: "O Director, e Censores da Academia Real da História Portuguesa dão licença ao Coronel Sebastião da Rocha Pitta, para usar o título de Acadêmico Supranumerário no livro intitulado História da América Portuguesa, vistas as Aprovações dos dois Acadêmicos, a que se cometteo o seu exame. Lisboa Occidental 6 de Dezembro de 1726". Portanto, essas duas aprovações foram as que produziram efeitos institucionais imediatos (a inclusão de Rocha Pitta na Academia como acadêmico supranumerário).

${ }^{38}$ Em uma passagem de sua dissertação de mestrado defendida em 2012, Pedro Telles da Silveira já chamava a atenção para o fato de que a obra de Rocha Pitta foi objeto de controvérsia já ao tempo de sua publicação: “(...) a indeterminação de seu estilo [o escolhido por Rocha Pitta para a escrita da História da América Portuguesa], que oscila entre a frase adequada a uma história e a apropriada a um panegírico. O que pouco se tem percebido é que essa controvérsia não se origina da recepção oitocentista da obra, pois ela já se consumara no século XVIII, caracterizando o debate acerca de sua aprovação para a imprensa. O primeiro parecer escrito sob a égide da Academia Real da História Portuguesa, datado de 10 de agosto de 1726 e de autoria de Antônio Rodrigues da Costa, traduz bem o problema: para o acadêmico, a História da América Portugueza 'é mais elogio, ou panegyrico, que Historia'. Se considerarmos que o debate acerca do que era a obra de Rocha Pita pode revelar uma dimensão acerca do que a historiografia poderia ser em inícios do Setecentos, perceberemos que o conjunto de pareceres, censuras e licenças escritos por terceiros assim como a dedicatória, o prólogo e a advertência originados do próprio punho de Rocha Pita são todos eles proposições a respeito da maneira mais correta de se perseguir a empresa historiográfica". SILVEIRA, Pedro Telles da. O cego e o coxo: Crítica e retórica nas dissertações históricas da Academia Brasílica dos Esquecidos (1724-1725). Dissertação apresentada ao Programa de Pós-Graduação em História da Universidade Federal de Ouro Preto como parte dos requisitos necessários à obtenção do grau de mestre. Mariana, maio de 2012, p. 96 (exceto o grifo que se encontra entre os colchetes, todos os outros grifos são do autor da dissertação) . De modo que a nossa linha de análise acaba por se aproximar da de Pedro Telles da Silveira, sobretudo no que tange à leitura dos elementos paratextuais da obra de Rocha Pitta para se proceder a uma sondagem dos princípios e debates a respeito da escrita histórica no mundo português da primeira metade do século XVIII. Agradecemos ao parecerista $\mathrm{n}^{\circ} 1$ por nos ter recomendado a leitura da citada dissertação. Leitura esta que pretendemos amadurecer para reflexões futuras referentes aos princípios de retórica e erudição verificados na historiografia ibero-americana. Cf. SILVEIRA, op. cit.

${ }^{39}$ Systema da Historia Ecclesiastica, \& Secular de Portugal, que há de escrever a Academia Real da História Portuguesa in Coleção dos documentos, estatutos e memórias da Academia Real da História Portuguesa..., não paginado.

40 Idem.

${ }^{41}$ PITTA, Sebastião da Rocha. História da América Portuguesa... "Advertências". Note-se que, pela declaração citada, o autor sugere que a natureza não deixará de frequentar o conjunto da sua narrativa. Deve-se ter em mente que o relato historiográfico do "corpo natural" da conquista lusitana é reflexo de uma preocupação de estabelecer a territorialidade da América Portuguesa. Para o conceito de territorialidade à luz da obra de Rocha Pitta, cf. KANTOR, Iris. Esquecidos e Renascidos: historiografia acadêmica luso-americana (1724-1759). São Paulo: Hucitec; Salvador, BA: Centro de Estudos Baianos IUFBA, 2004.

${ }^{42}$ ARISTÓTELES. Retórica. São Paulo: Editora WMF Martins Fontes, 2012, p. 191. Na edição que utilizamos, a passagem acima citada pertence a uma seção intitulada: "Adequação do estilo ao assunto". Para um estudo que possa oferecer uma dimensão da recepção da Retórica na Espanha do século XVII, cf. GRIGERA, Luisa López. Anotações de Quevedo à Retórica de Aristóteles. Campinas: Editora da UNICAMP, 2008. Considerando as trocas culturais peninsulares, não nos parece descabido estender essa recepção a Portugal. 
43 CABRERA DE CORDOBA. De historia, para entederla y escrivirla, Libro II, Discurso XIX. Citado em: CERQUEIRA, André Sekkel. A Donzela Alada: Reflexão sobre retórica e história em Portugal no século XVII. Dissertação apresentada ao Programa de Pós-Graduação em História Social do Departamento de História da Faculdade de Filosofia, Letras e Ciências Humanas da Universidade de São Paulo, para a obtenção do título de Mestre em História. São Paulo, 2017, p. 124. (Grifos nossos).

${ }^{44}$ MOTA, Isabel Ferreira da. A Academia Real da História - os intelectuais, o poder cultural e o poder monárquico no séc. XVIII. Coimbra: Edições Minerva, 2003; KAGAN, Richard. Los cronistas y la Corona: la política de la historia en España en las Edades Media y Moderna. Madri: Centro de Estudios Europa Hispánica, 2010; CLEMENTINO, Kleber. Política e historiografia nas narrativas lusocastelhanas seiscentistas da guerra holandesa no Atlântico Sul. Tese apresentada ao Programa de Pós-Graduação em História da Universidade Federal de Pernambuco como requisito para a obtenção do grau de doutor em História. Recife, julho de 2016.

${ }^{45}$ KANTOR, Iris. Esquecidos e Renascidos: historiografia acadêmica luso-americana (1724-1759). São Paulo: Hucitec; Salvador, BA: Centro de Estudos BaianosIUFBA, 2004.

${ }^{46}$ BARBOSA MACHADO, Diogo. Bibliotheca lusitana historica, critica, e cronologica. Na qual se comprehende a noticia dos authores portuguezes, e das obras, que compuserã̃ desde o tempo da promulgação da Ley da Graça até o tempo prezente (Volume 1). Lisboa, 1741, p. 375.

${ }^{47}$ Sobre a trajetória de António Rodrigues da Costa, cf. BARBOSA MACHADO, op. cit.

${ }^{48}$ BARBOSA MACHADO, volume 1, p. 375.

${ }^{49}$ No século XVIII, à luz do Tratado de Madrid, o ultramar português fazia parte das construções argumentativas com vistas a estabelecer traçados territoriais na América Portuguesa. A porção Oriental do ultramar ibérico aparece, no Tratado, como composição de uma interpretação diplomática - formulada por Alexandre de Gusmão - que revisava as disposições que começaram no Tratado de Tordesilhas ao de Utrecht ${ }^{49}$. De modo que a maturação do Tratado de Madrid reflete o estado em que se encontravam as prioridades ultramarinas do tempo de D. João $\mathrm{V}$ - prioridades que foram gradualmente delineadas no início da dinastia dos Bragança, a partir de 1640. O acordo assinado em 1750 parece concluir um longo processo de afirmação política. Independente das oposições formadas durante o reinado de D. José, o Tratado de Madrid constituiu um resultado prático da consolidação do conhecimento especializado - construído ao longo de um século pela Monarquia dos Bragança e por vassalos polígrafos. Nele, história, geografia e diplomacia formavam um bloco discursivo que conferia solidez aos interesses da Coroa. Cf. Tratado de limites das conquistas entre os muito altos e poderosos senhores d. João V, Rei de Portugal, e d. Fernando VI, rei de Espanha, assinado em 13 de janeiro de 1750, em Madrid, e ratificado em Lisboa a 26 do dito mês, e em Madrid a 8 de fevereiro do mesmo ano in Sousa, Octávio Tarquínio. Colecção documentos brasileiros, vol. 19, Rio de Janeiro, Livraria José Olympio Editora, 1939; CORTESÃO, Jaime. Alexandre de Gusmão e o Tratado de Madrid - parte 1, tomo 1 (1695-1735). Ministério das Relações Exteriores - Instituto RioBranco. Rio de Janeiro; RIO-BRANCO, Miguel Paranhos. Alexandre de Gusmão e o Tratado de 1750. Brasília: FUNAG, 2010; FURTADO, Júnia Ferreira. Guerra, diplomacia e mapas: a Guerra da Sucessão Espanhola, o Tratado de Utrecht e a América portuguesa na cartografia de D' Anville. Topoi, v. 12, n. 23, jul-dez. 2011, p. 66-83; KANTOR, Iris. Esquecidos e Renascidos...

${ }^{50}$ BLUTEAU, Rafael. Vocabulario portuguez e latino, aulico, anatomico, architectonico, bellico, botanico, brasilico, comico, critico, chimico, dogmatico, dialectico, dendrologico, ecclesiastico, etymologico, economico, florifero, forense, fructifero... autorizado com exemplos dos melhores escritores portugueses, e latinos... 10 Vols. Coimbra: no Collegio das Artes da Companhia de Jesu, 1712-1728, volume 6, p. 221.

${ }^{51}$ Para uma reflexão sobre o panegírico à luz da História de Rocha Pitta, cf. SILVEIRA, Pedro Telles da. O cego e o coxo: Crítica e retórica nas dissertações históricas da Academia Brasílica dos Esquecidos (1724-1725). Dissertação apresentada ao Programa de Pós-Graduação em História da Universidade Federal de Ouro Preto como parte dos requisitos necessários à obtenção do grau de mestre. Mariana, maio de 2012.

${ }^{5}$ PÉCORA, Alcir. A história como colheita rústica de excelências in SCHWARTZ, Stuart e PÉCORA, Alcir (org.) As excelências do governador: O panegírico fúnebre a d. Afonso Furtado, de Juan Lopes Sierra (Bahia, 1676). São Paulo: Companhia das Letras, 2002, p. 49. O itálico é do autor.

${ }^{53}$ Idem, p. 49. Os itálicos são do autor.

${ }^{54}$ Aprovação de D. António Caetano de Souza in PITTA, op. cit. Os itálicos são nossos.

${ }_{55}$ MOTA, op. cit., p. 48

${ }^{56}$ BURKE, op. cit., passim.

${ }^{57}$ MOTA, op. cit.

${ }^{58}$ Essas considerações acerca da censura e impressão das obras acadêmicas se encontram fundamentadas, novamente, pelo estudo de Isabel Ferreira da Mota, que ainda constitui uma importante referência a respeito do funcionamento da Academia Real da História Portuguesa. Entretanto, convém matizar o poder censório da Academia, do contrário, corre-se o perigo de diminuir o papel de instituições como o Santo Ofício. Com efeito, ao final das aprovações de membros do Santo Ofício à História de Rocha Pitta (aprovações que, por motivos de delimitação, não foram objeto de análise no presente artigo), lê-se a seguinte declaração: "Que se possa imprimir, vistas as licenças do Santo Ofício, e Ordinário, e depois de impresso tornará à Mesa para se conferir, e taixar [sic.], que sem isso não correrá. Lisboa Occidental $1^{\circ}$ de Agosto de 1727 ". Este fragmento parece estar em descordo com a regra geral formulada por Isabel Ferreira da Mota em seu estudo: "Embora as aprovações do Santo Ofício e do Ordinário tenham existido, elas não figuram nos livros. Portanto, para o leitor que os abre e os lê elas não existem. E isto é extremamente importante porque, numa sociedade onde os órgãos censórios eram a instância de legitimação, de súbito saem a público continuadamente obras que se autolegitimam. Ou, melhor dizendo, a Academia autolegitima-se perante o público". MOTA, op. cit. pp. 48-49. Reiteramos que há muito por dizer acerca das atribuições 
relativas à censura de obras historiográficas (ao que parece, a cultura escrita lusófona não está imune aos clássicos desencontros de alçadas e jurisdições verificadas no Antigo Regime).

${ }^{59}$ Importa considerar que a política da Monarquia Bragantina nos séculos XVII e XVIII era fundamentalmente externa. É preciso ter isto em mente ao refletir sobre o papel de homens de letras na cultura política portuguesa do Antigo Regime. Eles estavam na diplomacia, na parenética, nas obras de história, geografia e genealogia. Não raro, um mesmo homem poderia atuar em embaixadas e em arquivos. Cada qual a seu modo, estes sujeitos ajudaram na construção da nova Monarquia perante o cenário europeu, bem como participaram da atualização das glórias de patronímicos e da delimitação de territórios ultramarinos. Sobre a diplomacia portuguesa nos séculos XVII e XVIII, cf. CARDIM, Pedro; MONTEIRO, Nuno Gonçalo; FELISMINO, David. A diplomacia portuguesa no Antigo Regime. Perfil sociológico e trajectórias in MONTEIRO, Nuno Gonçalo, CARDIM, Pedro \& CUNHA, Mafalda Soares da (coord.). Optima Pars: Elites Ibero-Americanas do Antigo Regime. Lisboa: ICS. Imprensa de Ciências Sociais, 2005; MELLO, Evaldo Cabral de. O Negócio do Brasil: Portugal, os Países baixos e o Nordeste (1641-1669). São Paulo: Companhia das Letras, 2011; MARCOS, David Martín. Península de recelos - Portugal y España, 1668-1715. Madrid: Marcial Pons Ediciones de Historia, 2014.

${ }^{60}$ CADORnEGA, António de Oliveira de. História Geral das Guerras Angolanas. 3 tomos. Divisão Geral das Colónias, 1940 [Final do século XVII].

${ }^{61}$ MENEZES, D. Luís de (Conde da Ericeira). História do Portugal Restaurado. Lisboa: na Oficina de João Galrão (16791698).

Referências bibliográficas

AGUILAR PERDOMO, María del Rosario. La recepción de los libros de caballerías en el siglo XVI: a propósito de los lectores en el Quijote. Literatura: teoría, historia, crítica 7 (2005): pp. 45-67.

ALEXANDRE JÚNIOR, Manuel. Introdução in ARISTÓTELES. Retórica. São Paulo: Editora WMF Martins Fontes, 2012.

BERRIO, Antonio García. EI "patrón” renacentista de Horacio y los tópicos teóricoliterarios del Siglo de Oro español. Actas del cuarto Congreso Internacional de Hispanistas, 1971.

ARISTÓTELES. Retórica. São Paulo: Editora WMF Martins Fontes, 2012.BOUZA, Fernando. Del Escribano a la Biblioteca - La Civilización Escrita Europea en la Alta Edad Moderna (Siglos XV-XVII). Madrid: Editorial Síntesis, 1997.

BARBOSA MACHADO, Diogo. Bibliotheca lusitana historica, critica, e cronologica. Na qual se comprehende a noticia dos authores portuguezes, e das obras, que compuserã̃ desde o tempo da promulgação da Ley da Graça até o tempo prezente (Volume 1). Lisboa, 1682.

BLUTEAU, Rafael. Vocabulario portuguez e latino, aulico, anatomico, architectonico, bellico, botanico, brasilico, comico, critico, chimico, dogmatico, dialectico, dendrologico, ecclesiastico, etymologico, economico, florifero, forense, fructifero... autorizado com exemplos dos melhores escritores portugueses, e latinos... 10 Vols. Coimbra: no Collegio das Artes da Companhia de Jesu, 1712-1728.

BOUZA, Fernando. Para qué imprimir. De autores, público, impresores y manuscritos en el Siglo de Oro. Cuadernos de Historia Moderna, número 18, Servicio de Publicaciones. Universidad Complutense. Madrid, 1997.

BURKE, Peter. As fortunas d'O cortesão: a recepção europeia a O Cortesão de Castiglione. São Paulo: Editora da Universidade Estadual Paulista, 1997.

CARDIM, Pedro; MONTEIRO, Nuno Gonçalo; FELISMINO, David. A diplomacia portuguesa no Antigo Regime. Perfil sociológico e trajectórias in MONTEIRO, Nuno Gonçalo, CARDIM, Pedro \& CUNHA, Mafalda Soares da (coord.). Optima Pars: Elites Ibero-Americanas do Antigo Regime. Lisboa: ICS. Imprensa de Ciências Sociais, 2005. 
CASTRO, Ivo. Sobre a data da introdução na Península Ibérica do ciclo arturiano da Post-Vulgata. Bulletin of Hispanic Studies, 1975.

CERQUEIRA, André Sekkel. A Donzela Alada: Reflexão sobre retórica e história em Portugal no século XVII. Dissertação apresentada ao Programa de Pós-Graduação em História Social do Departamento de História da Faculdade de Filosofia, Letras e Ciências Humanas da Universidade de São Paulo, para a obtenção do título de Mestre em História. São Paulo, 2017.

CLEMENTINO, Kleber. Política e historiografia nas narrativas lusocastelhanas seiscentistas da guerra holandesa no Atlântico Sul. Tese apresentada ao Programa de PósGraduação em História da Universidade Federal de Pernambuco como requisito para a obtenção do grau de doutor em História. Recife, julho de 2016.

COLEÇÃO DOS DOCUMENTOS, estatutos e memórias da Academia Real da História Portuguesa, que neste ano de 1721, se compuseram e se imprimiram por ordem dos censores, dedicada a el rei nosso senhor, seu augustissímo protetor e ordenada pelo conde de Villamayor, secretário da mesma academia. Lisboa Ocidental, na oficina de Pascoal da Sylva, Impresso de S. Magestade Real. MDCCXXI.

CLUNY, Isabel. A Guerra de Sucessão de Espanha e a Diplomacia Portuguesa. Penélope, $\mathrm{n}^{\circ}$ 26, 2002, pp. 63-92.

CORTESÃO, Jaime. Alexandre de Gusmão e o Tratado de Madrid - parte 1, tomo 1 (1695-1735). Ministério das Relações Exteriores - Instituto Rio-Branco. Rio de Janeiro.

CURTIUS, Ernest Robert. Literatura Europeia e Idade Média Latina. São Paulo: Hucitec: Edusp, 1996.

DÍAZ-TOLEDO, Aurelio Vargas. Os livros de cavalarias renascentistas nas histórias da literatura portuguesa. Universidad Complutense de Madrid/Centro de Estudios Cervantinos. Península. Revista de Estudos Ibéricos, no 3, 2006: 233-247.

FORTES, Manuel de Azevedo. O Engenheiro Portuguez (2 tomos). Lisboa Ocidental: Na Oficina de Manoel Fernandes da Costa, 1728.

FURTADO, Júnia Ferreira. Guerra, diplomacia e mapas: a Guerra da Sucessão Espanhola, o Tratado de Utrecht e a América portuguesa na cartografia de D' Anville. Topoi, v. 12, n. 23, jul-dez. 2011, p. 66-83.

GINZBURG, Carlo. Mitos, Emblemas, Sinais: morfologia e história. São Paulo: Companhia das Letras, 2014.

GRIGERA, Luisa López. Anotações de Quevedo à Retórica de Aristóteles. Campinas: Editora da UNICAMP, 2008.

Sobre el realismo literário Del Siglo de Oro. Actas del VIII Congreso de la Asociación Internacional de Hispanistas, 1986.

KAGAN, Richard. Los cronistas y la Corona: la política de la historia en España en las Edades Media y Moderna. Madri: Centro de Estudios Europa Hispánica, 2010.

KANTOR, Iris. Esquecidos e Renascidos: historiografia acadêmica luso-americana (1724-1759). São Paulo: Hucitec; Salvador, BA: Centro de Estudos Baianos IUFBA, 2004.

LAÍlLA, Luis Sánchez. "Dice Aristóteles": la reescritura de la Poética en los Siglos de Oro. CRITICÓN. Número 79 (2000).

MARCOS, David Martín. Península de recelos - Portugal y España, 1668-1715. Madrid: Marcial Pons Ediciones de Historia, 2014.

MELlO, Evaldo Cabral de. O Negócio do Brasil: Portugal, os Países baixos e o Nordeste (1641-1669). São Paulo: Companhia das Letras, 2011. 
MONGELLI, Lênia Márcia; GOUVEIA FERNANDES, Raúl Cesar \& MAUÉS, Fernando. Introducão - Pela Fé, Pelo Império, Por Amor in MORAES, Francisco de. Palmeirim de Inglaterra. Cotia: Ateliê Editorial; Campinas: Editora da Unicamp, 2016.

MORETTI, Franco. Romance: história e teoria. São Paulo: Novos estudos - CEBRAP número 85, 2009.

MOTA, Isabel Ferreira da. A Academia Real da História - os intelectuais, o poder cultural e o poder monárquico no séc. XVIII. Coimbra: Edições Minerva, 2003.

OLIVAL, Fernanda. As Ordens Militares e o Estado Moderno - honra, mercê e venalidade em Portugal (1641-1789). Estar, 2001.

PÉCORA, Alcir. A história como colheita rústica de excelências in SCHWARTZ, Stuart e PÉCORA, Alcir (org.) As excelências do governador: $O$ panegírico fúnebre a d. Afonso Furtado, de Juan Lopes Sierra (Bahia, 1676). São Paulo: Companhia das Letras, 2002.

PESSOTI, Bruno Casseb. Ajuntar manuscritos, e convocar escritores: o discurso histórico institucional no setecentos luso-brasileiro. Dissertação apresentada ao Programa de PósGraduação em História, Faculdade de Filosofia e Ciências Humanas, Universidade Federal da Bahia, como requisito parcial para obtenção do grau de Mestre em História. Salvador, 2009.

PITTA, Sebastião da Rocha. História da América Portuguesa, desde o anno de mil e quinhentos do seu descobrimento, até o ano mil e setecentos e vinte e quatro. Lisboa Ocidental, na Oficina de Joseph Antonio da Silva, impressor da Academia Real, 1730.

REDONDO, Fernando Gómez. Historia de la Prosa Medieval Castellana, I - La creación del discurso prosístico: el entramado cortesano. Madrid: Cátedra, 1998.

RIO-BRANCO, Miguel Paranhos. Alexandre de Gusmão e o Tratado de 1750. Brasília: FUNAG, 2010.

SILVEIRA, Pedro Telles da. O cego e o coxo: Crítica e retórica nas dissertações históricas da Academia Brasílica dos Esquecidos (1724-1725). Dissertação apresentada ao Programa de Pós-Graduação em História da Universidade Federal de Ouro Preto como parte dos requisitos necessários à obtenção do grau de mestre. Mariana, maio de 2012.

SINKEVISQUE, Eduardo. Historiarum Copia, História Seleta: O Tratado Político (1715) de Sebastião da Rocha Pita in Pita, Sebastião da Rocha. Tratado Político (1715). Estudo introdutório, transcrição, índices, notas e estabelecimento do texto por Eduardo Sinkevisque; prefácio de João Adolfo Hansen. São Paulo: Edusp.

SOARES, Sérgio Cunha. Nobreza e Arquétipo Fidalgo - A propósito de um Livro de Matrículas de Filhamentos (1641-1724). Revista de História das Ideias. Vol. 19, 1997.

TORGAL, Luís Reis. Ideologia Política e Teoria do Estado na Restauração (2 vols.). Coimbra: Biblioteca Geral da Universidade, 1981.

TRATADO DE LIMITES das conquistas entre os muito altos e poderosos senhores d. João V, Rei de Portugal, e d. Fernando VI, rei de Espanha, assinado em 13 de janeiro de 1750, em Madrid, e ratificado em Lisboa a 26 do dito mês, e em Madrid a 8 de fevereiro do mesmo ano in Sousa, Octávio Tarquínio. Colecção documentos brasileiros, vol. 19, Rio de Janeiro, Livraria José Olympio Editora, 1939.

XAVIER, Ângela Barreto \& HESPANHA, António Manuel. Redes Clientelares in MATTOSO, José \& HESPANHA, António Manuel. História de Portugal - O Antigo Regime. Editorial Estampa, 1998.

YATES, Frances Amelia. A Arte da Memória. Campinas: Editora da Unicamp, 2007. 